\title{
ПУБЛИКАЦИИ
}

DOI: http://doi.org/10.15688/nav.jvolsu.2016.1.5

UDC 930.26(470+571):903.53

LBC 63.48(2)-427.1

\section{FUNERARY MONUMENTS OF SHLYAKHOVSKY BURIAL MOUND OF THE EARLY IRON AGE}

\author{
Valeriy M. Klepikov \\ Volgograd State University, Volgograd, Russian Federation
}

\begin{abstract}
The article is devoted to the publication of the early iron age funerary monuments of the Shlyahovsky burial mound, located in the Volga-Don interfluve. There is description of the two burials of pre-Sauromatian time, two of them belong to early Sarmatian time and the other two are related to the late Sarmatian time. The author analyzes the peculiarities of the funeral rite and clothing inventory, identifies chronological position and suggests dates of burial complexes.
\end{abstract}

Key words: pre-Sauromatian time, Early Sarmatian culture, Late Sarmatian culture, Volga-Don interfluve.

УДК 930.26(470+571):903.53

ББК 63.48(2)-427.1

\section{ПОГРЕБЕНИЯ РАННЕГО ЖЕЛЕЗНОГО ВЕКА КУРГАННОГО МОГИЛЬНИКА ШЛЯХОВСКИЙ}

\author{
Валерий Михайлович Клепиков \\ Волгоградский государственный университет, г. Волгоград, Российская Федерация
}

\begin{abstract}
Аннотация. Статья посвящена публикации погребальных памятников раннего железного века из могильника Шляховский, расположенного в Волго-Донском междуречье. Дано описание двух погребений предсавроматского времени, двух - раннесарматских и двух, относящихся к позднесарматскому времени. Анализируются особенности погребального обряда и вещевого инвентаря, определены хронологические позиции и предложена датировка погребальных комплексов.

Ключевые слова: предсавроматское время, раннесарматская культура, позднесарматская культура, Волго-Донское междуречье.
\end{abstract}

В 1989 г. археологическая экспедиция Волгоградского государственного университета исследовала курганы на территории Фро๑ ловского района Волгоградской области в зоне 로 строительства I очереди Фроловской оросиi тельной системы. Экспедицией было раско๓े пано 15 курганов, объединенных в 3 группы, расположенные на пахотном поле колхоза «Путь Ленина» северо-западнее хут. Шляховский. Из 78 погребений 2 были отнесены к эпо- хе энеолита, 56 были срубного времени, 2 киммерийского, 4 - сарматского, 6 - средневекового периода. 8 погребений не были атрибутированы из-за отсутствия вещевого материала и разрушенности погребений.

Наиболее яркие энеолитические и средневековые комплексы были опубликованы вскоре после раскопок [Клепиков, 1994, с. 97102; Круглов, 1993, с. 138-151], однако погребения, относящиеся к раннему железному веку, 
были востребованы исключительно в статистических подсчетах. В то же время они имеют самостоятельную ценность, представляя интерес как для киммерийского времени, так и для раннесарматского и позднесарматского периодов.

Курганная группа Шляховский I располагалась на пахотном поле, на возвышенности, в 1,1 км к ЗС3 от хут. Шляховский.

Курган 1. Средняя высота кургана по нивелировке $-0,43$ м. В плане курган имел форму овала. Длина по линии 3-В - 30 м, по линии С-Ю - 26 м. Насыпь сооружена над погребением срубной культуры.

Погребение 3 (впускное) было обнаружено на расстоянии 2,65 м к востоку от центрального репера. Могильная яма удлиненной овальной формы, длинной осью ориентирована по линии ВСВ-ЗЮЗ. Длина ямы по дну 2 м, ширина ямы $-0,7$ м, глубина от современной поверхности - 1,52 м. На дне могильной ямы лежал скелет мужчины 20-25 лет, вытянуто, левая рука вдоль туловища, кистью на тазовых костях, правая рука вытянута и отведена вправо. Черепом и позвоночным столбом погребенный ориентирован на ЗЮЗ. Вещей нет (рис. 1,1).

Курган 3. Средняя высота кургана по нивелировке - 1,7 м, насыпь в плане имела форму овала, вытянутого по линии запад восток. Длина по линии 3-В - 42 м, по линии C-Ю - 32 м. Курган сооружен над погребением срубной культуры.

Погребение 1 (впускное). Погребение обнаружено на расстоянии 2,6 м к $3 Ю 3$ от центрального репера на глубине 0,85 м от современной поверхности. Могильная яма в насыпи почти не прослеживалась. Зафиксирована лишь северная стенка. Вероятно, яма была узкой прямоугольной с закругленными углами. Скелет взрослого человека лежал на спине вытянуто, головой и позвоночным столбом ориентированный на запад. Левая рука лежала вдоль туловища, правая - кистью на тазовых костях (рис. 1,2).

1. Перед лицевыми костями с северной стороны на расстоянии 5 см стоял глиняный лепной сосуд. Сосуд имел высокое расширяющееся к тулову горло с сильно отогнутым наружу венчиком, биконическое тулово, оттянутое ко дну, и плоское дно с круговым защи- пом. Тесто в изломе черное с примесью толченой керамики. Высота сосуда - 24,1 см, диаметр по венчику - 11,5 см, диаметр горла $-9,5$ см, диаметр тулова $-22,8$ см, диаметр по дну $-9,8$ см, толщина стенок $-0,9$ см (рис. 1,3).

2. В области живота под локтевым суставом лежал бронзовый нож, однолезвийный, черешковый. Длина лезвия - 8,2 cм, ширина сохранившейся части $-1,8$ см, длина широкой части $-2,5$ см (рис. 1,4).

Курганная группа Шляховский II располагалась на том же пахотном поле, что и Шляховский I, через балку от нее, на расстоянии 1 км 50 м к СВ от первой группы.

Курган 4 распахан. Средняя высота кургана по нивелировке - 0,68 м, диаметр насыпи - 22 м. Основное погребение срубное.

Погребение 1 (впускное) было обнаружено на расстоянии 2 м к 3С3 от центрального репера. Могильная яма прямоугольной формы длинной осью была ориентирована по линии С-Ю. Длина ямы - 2,27 м, ширина -0,83 м, глубина от современной поверхности $-1,09$ м. В засыпи ямы была видна тонкая прослойка камышового перекрытия, провалившаяся в яму. На дне могильной ямы лежал скелет женщины 55-60 лет вытянуто на спине, головой и позвоночным столбом ориентированный на юг, лицевыми костями к СВ. Руки уложены вдоль туловища. Левая рука слабо согнута в локте и кистью на тазовой кости. Ноги вытянуты. Погребенная лежала в гробовище, остатки которого прослежены над костями погребенной и под ними. Дно гробовища было, видимо, выстелено камышовой подстилкой, следы которой обнаружены под костяком (рис. 2,1).

1. За головой в $15 \mathrm{~cm}$ от южной стенки лежал треугольный обломок дисковидного бронзового зеркала с валиком по краю. Ширина валика $-1,1$ см, толщина валика $-0,4 \mathrm{~cm}$, толщина плоской части зеркала $-0,5 \mathrm{~cm}$, восстановленный диаметр диска- 14 см (рис. 2,4).

2. Под черепом погребенной и у правого плеча найдены кусочки реальгара (6 шт.).

3. У левого плеча погребенной найден кусок мела, в ногах еще один.

4. В области запястий обеих рук и на тазовых костях собрано 49 бус (рис. 2,3). Из них:

a) округлая поперечно-сжатая с внутренним серебрением, отверстие овальное, с од- 
ной стороны фаска - 1 шт. Высота - 5 мм, ширина -3 мм, длина - 5 мм, длина отверстия - 2 мм;

б) серо-фиолетовые прозрачные и полупрозрачные стеклянные бусы, округлые, продольно сжатые - 41 шт. Высота - 5-6 мм, ширина - 5-6 мм, длина $-4,8$ мм, диаметр отверстия - 1-2 мм;

в) округлые, прозрачные поперечно-сжатые бусы из лимонно-желтого стекла - 3 шт. Высота -6 мм, ширина -4 мм, длина -6 мм, диаметр отверстия - 3 мм;

г) округло-бугристые бусы с внутренним золочением - 3 шт. Высота - 5 мм, ширина 3 мм, длина -5 мм, диаметр отверстия - 3 мм;

д) фрагмент меловой цилиндрической пронизи очень плохой сохранности -1 шт.

5. В области щиколоток собрана 41 бусина (рис. 2,3). Из них:

е) уплощенно-биконические бусы из темно-желтого стекла - 12 шт. Высота - 5-6 мм, длина - 5-6 мм, ширина - 2-4 мм, диаметр отверстия - 2-3 мм;

ж) цилиндрические стеклянные с внутренним серебрением - 15 шт. Высота -4 мм, ширина $-2-3$ мм, длина - 4 мм, диаметр отверстия -2 мм;

3) округлые с внутренним серебрением 4 шт. Высота - 5 мм, ширина -3 мм, длина 5 мм, диаметр отверстия - 2 мм;

и, к) округлые продольно-сжатые серофиолетового цвета (как у пояса) - 2 шт. Высота - 5 мм, ширина - 6 мм, длина -5 мм, диаметр отверстия - 2 мм;

л) округлая бусина из янтарного прозрачного стекла - 1 шт. Высота - 6 мм, ширина 4 мм, длина - 6 мм, диаметр отверстия - 2 мм;

м) округлые бусы из лимонно-желтого прозрачного стекла, некоторые с закраинками -7 шт. Высота - 5 мм, ширина - 6 мм, длина - 5 мм, диаметр отверстия - 3 мм.

6. В ногах погребенной стоял глиняный лепной сосуд с шаровидным туловом и плоским дном. Верхняя часть сосуда разрушена. Сохранился обломок венчика. Судя по нему, сосуд имел короткое горло и отогнутый наружу венчик. Тесто в изломе черное с примесью керамического боя и известняковых (?) вкраплений. Высота сохранившейся части тулова - 20,2 см, предполагаемая высота всего сосуда $-23,3$ см, диаметр тулова $-19,9$ см, диаметр дна -9 см, толщина стенки $-0,9$ см, предполагаемый диаметр по венчику $-2,9$ см (рис. 2,2).

7. Рядом с описанным сосудом в ногах стояла половина маленького лепного сосуда с плоским дном, округлым туловом, выделенным плечиком, прямым высоким горлом и слабо отогнутым наружу венчиком. Тесто в изломе черное, без видимых вкраплений. Высота сосуда - 10,5 см, диаметр по венчику 7 см, диаметр тулова $-9,6$ см, диаметр по дну -6 см, толщина стенки $-0,7$ см (рис. 2,5).

8. Вдоль правой ноги в области плюсны лежала лопатка овцы.

9. Под позвоночником в области пояса найдена круглая уплощенная галька.

Курганная группа Шляховский III располагалась в 3 км к северо-западу от группы Шляховский I.

Курган 2 располагался на пахотном поле, но не распахивался из-за больших размеров; в прошлом на нем была установлена деревянная триангуляционная вышка. Высота кургана по нивелировке 2,46 м, диаметр насыпи37 м. Основное погребение срубное.

Погребение 1 (впускное) было обнаружено на расстоянии 0,4 м к западу от центрального репера. Могильная яма прямоугольной формы длинной осью была ориентирована по линии С-Ю. Длина ямы 3,3 м, ширина в центре $-0,9$ м, в северной части до 1 м. Яма имела в южной части восточной стенки небольшой подбой, где обнаружен череп человека. Ширина подбоя - 0,2 м, глубина от современной поверхности - 2,55 м. В погребении на дне ямы зафиксирован контур деревянного гробовища прямоугольной формы длиной 2,35 м, шириной до 0,6 м. Сверху гробовище было перекрыто деревянными плахами. Под перекрытием прослежены плохо сохранившиеся кости погребенного. Видимо, прорытая сверху яма приводила к постоянному промачиванию погребения, так как от костей сохранились в основном лишь белесые следы. Судя по прослеженным костям правой руки и правой ноги, погребенный лежал на спине вытянуто, руки вдоль туловища, головой ориентирован на север (рис. 3,1 ).

1. Вдоль берцовой кости левой ноги наконечниками на юг были положены стрелы. Железные наконечники стрел сильно коррори- 
зированы и сплавлены в одну массу. Тем не менее ясно, что это трехлопастные черешковые наконечники стрел с треугольной головкой и срезанными под острым углом лопастями. Длина головки - 2,3 см, длина сохранившихся обломков черешков $-2,7$ см. Черешки толщиной 0,4 см, заострены к концу. Продолжением наконечников были древки стрел, изготовленные из дерева, длиной сохранившейся части до 22 см, несколько уплощенные, в сечении 1,5 мм $\times 2,5$ мм. Основания стрел имели утолщения 4,5 мм с вырезом для наложения тетивы. Длина выреза 6 мм. Древки и утолщения окрашены в красный цвет (рис. 3,3,4).

2. В ногах погребенного обнаружен сильно коррозированный обломок железного предмета.

3. За костями плюсны левой ноги на деревянном перекрытии найден раздавленный глиняный лепной кувшин с небольшой петлевидной ручкой. Кувшин имеет плоское дно, круглое тулово, прямое горло и отогнутый наружу венчик. Горло от плечика отделяется круговым валиком, сформированным из теста сосуда. Плечико орнаментировано круговой зигзагообразной линией, под которой проходит прямая круговая линия, также прочерченная острым концом палочки. Ручка орнаментирована «елочкой», нанесенной косыми насечками. Тесто в изломе черное с примесью песка. Высота сосуда 22,9 см, диаметр венчика $-11,4 \mathrm{~cm}$, высота ручки -6 см, диаметр ручки 1,6 $22 \mathrm{~cm}$, толщина $-0,8$ см (рис. 3,2 ).

4. На одном из фрагментов стенки кувшина лежал округлый кусок смолы диаметром 2 см.

5. Под деревянным перекрытием рядом с кувшином лежал обломок кости крупного домашнего животного. Сохранность плохая.

Курган 5 располагался на пахотном поле, насыпь распахана. Высота кургана по нивелировке - 0,76 м, диаметр насыпи - 35 м. Основное погребение относится к срубной культуре.

Погребение 2 (впускное) было обнаружено в насыпи под центральным репером на глубине 0,3 м. Могильная яма не прослеживалась. Скелет женщины, частично разрушенный распашкой, лежал на спине вытянуто, головой и позвоночным столбом ориентированный на север. Череп разрушен, не сохранились кости правой руки и ног, за исключением ле- вой бедренной кости. Правая рука вытянута вдоль туловища. Ноги, видимо, также вытянуты. У левого плеча, на левой плечевой кости, лежали кости рук, ребра и фрагменты черепа младенца. Под скелетом погребенной прослежено дерево гробовища (рис. 4,1).

1. У левой бедренной кости лежал в обломках глиняный лепной горшок с плоским дном, округлым туловом, расширяющимися горлом и отогнутым наружу венчиком. Тесто в изломе черное, с примесью толченой керамики и крупнозернистого песка. Высота сосуда - 14,9 см, диаметр венчика - 12 см, диаметр тулова 13,5 см, дна $-8,6$ см, диаметр горла $-10,3$ см, толщина стенки - 1,2 см (рис. 4,2).

Курган 7 также располагался на пашне у края поля. Высота кургана по нивелировке 0,68 м, диаметр насыпи - 35 м. Основное погребение относится к срубной культуре.

Погребение 2 (впускное) было обнаружено на расстоянии 3,3 м к востоку от центрального репера на глубине 0,8 м от современной поверхности. Контуры могильной ямы не прослеживались. Погребенный (мужчина 3540 лет) лежал вытянуто на спине, головой и позвоночным столбом ориентирован на север. Левая рука вытянута вдоль туловища, правая отсутствует. Ноги вытянуты. Под погребенным прослежены следы древесной подстилки (рис. 4,3).

1. Вдоль правой руки лежали обломки клинка железного меча. Длина сохранившейся части - 14,5 см, ширина - до 3,5 см, толщина - 1,2 см. Клинок обоюдоострый, ромбовидный в сечении (рис. 4,5).

2. Между берцовых костей погребенного обнаружены кости ноги барана.

3. У стопы левой ноги стоял раздавленный землей глиняный лепной сосуд с плоским дном, округлым туловом, короткой шейкой и отогнутым наружу венчиком. Тесто в изломе черное с примесью мелкотолченой керамики. Высота сосуда - 14 см, диаметр венчика 10,8 см, диаметр горла - 9,3 см, диаметр тулова $-13,7$ см, диаметр дна -7 см, толщина стенки - 0,65 см (рис. 4,4).

Среди погребений могильника Шляховский раннего железного века два комплекса можно отнести к предсавроматскому времени (Шляховский I, курган 1, погребение 3, и курган 3, погребение 1). Погребальный обряд 
и небогатый набор погребального инвентаря вписывается в уже внушительный список памятников, опубликованный в свое время исследователями Нижнего Поволжья [Мамонтов, 1980; Дворниченко, 1981]. Вытянутое положение погребенных с ориентировкой к западу становится преобладающей традицией к концу VIII - началу VII в. до н. э. [Лукьяшко, 1999, с. 142]. Бронзовый черешковый нож с прогнутой спинкой и уступом у перехода к черешку (рис. 1,4) имеет аналогии на Нижнем Дону и Северном Кавказе и датируется в указанных хронологических рамках [Лукьяшко, 1999, с. 156-157]. Глиняная корчага удлиненных пропорций с выделенной придонной частью и высоким горлом (рис. 1,3) хорошо известна в предскифском керамическом комплексе и также может быть отнесена к VIIIVII вв. до н. э. [Лукьяшко, 1999, с. 174-175].

Двумя погребениями представлен раннесарматский период. Впускные погребения с вытянутым положением костяка характерны для этого периода. Южная ориентировка женщины, погребенной в деревянном гробовище (Шляховский II, курган 4, погребение 1), также традиционна для раннесарматской культуры. Найденный в головах треугольный обломок бронзового зеркала с валиком по краю частая находка в комплексах раннесарматской культуры и позволяет датировать погребение III-І вв. до н. э. [Скрипкин, 1990, с. 151]. К этому же времени следует отнести глинятые лепные сосуды, традиционные для разви- той раннесарматской культуры. Горшок с коротким цилиндрическим горлом, шаровидным туловом и плоским дном (рис. 2,2 ) имеет многочисленные аналогии в комплексах III - cередины II в. до н. э. Нижнего Поволжья [Клепиков, 2002, рис. 16] и Приуралья [Моргунова и др., 2003, рис. 98,4]. Нижнюю границу определяют стеклянные бусы с внутренней позолотой, неизвестные в погребениях ранее III в. до н. э. [Алексеева, 1978, с. 29].

Погребение 1 из кургана 2 (Шляховский III) также может быть в целом датировано в хронологических границах III-I вв. до н. э. Лепные кувшины с петлевидной ручкой и прочерченным орнаментом по плечику не редкость раннесарматском инвентаре [Скрипкин, 1990, рис. 45], как и железные трехлопастные черешковые наконечники стрел. Интерес представляет ориентировка головой на север, что является инновацией для раннесарматских погребений, сужая время бытования до II-I вв. до н. э. [Клепиков, 2014, с. 51-55].

Еще два впущенных в насыпь погребения из могильника Шляховский III (курган 5, погребение 2, и курган 7, погребение 2) могут быть определены как позднесарматские по положению и ориентировке костяков в северный сектор. Невозможность проследить границы ям, невыразительные лепные плоскодонные горшки с отогнутым наружу венчиком, обломок лезвия меча дают возможность определить лишь общие временные границы в пределах II-IV вв. н. э. 


\section{ИЛЛЮСТРАЦИИ}
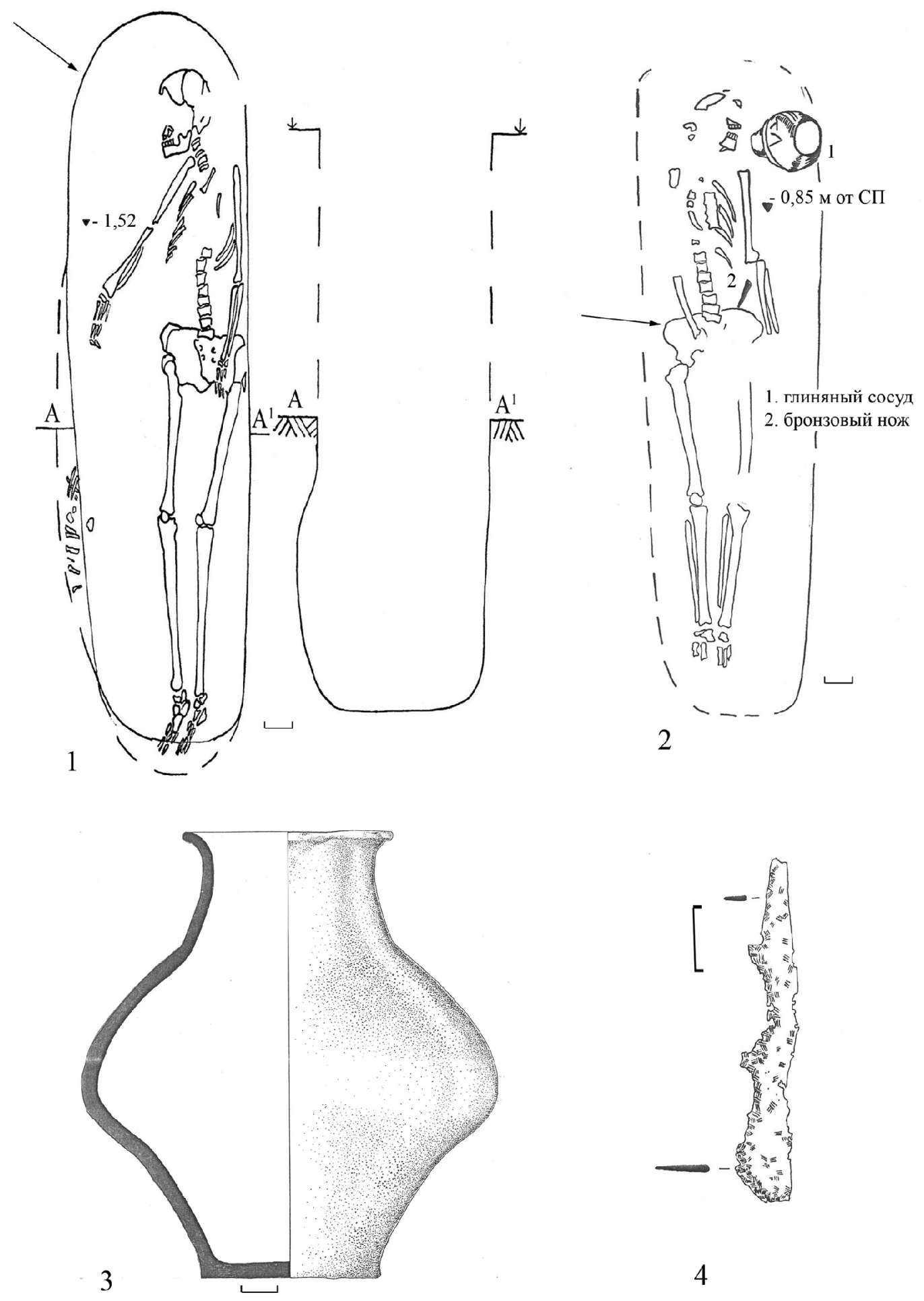

Рис. 1. Погребения предсавроматского времени. Могильник Шляховский I:

1 - курган 1, погребение $3 ; 2$ - курган 3, погребение $1 ; 3$ - глиняная корчага; 4 - бронзовый нож 


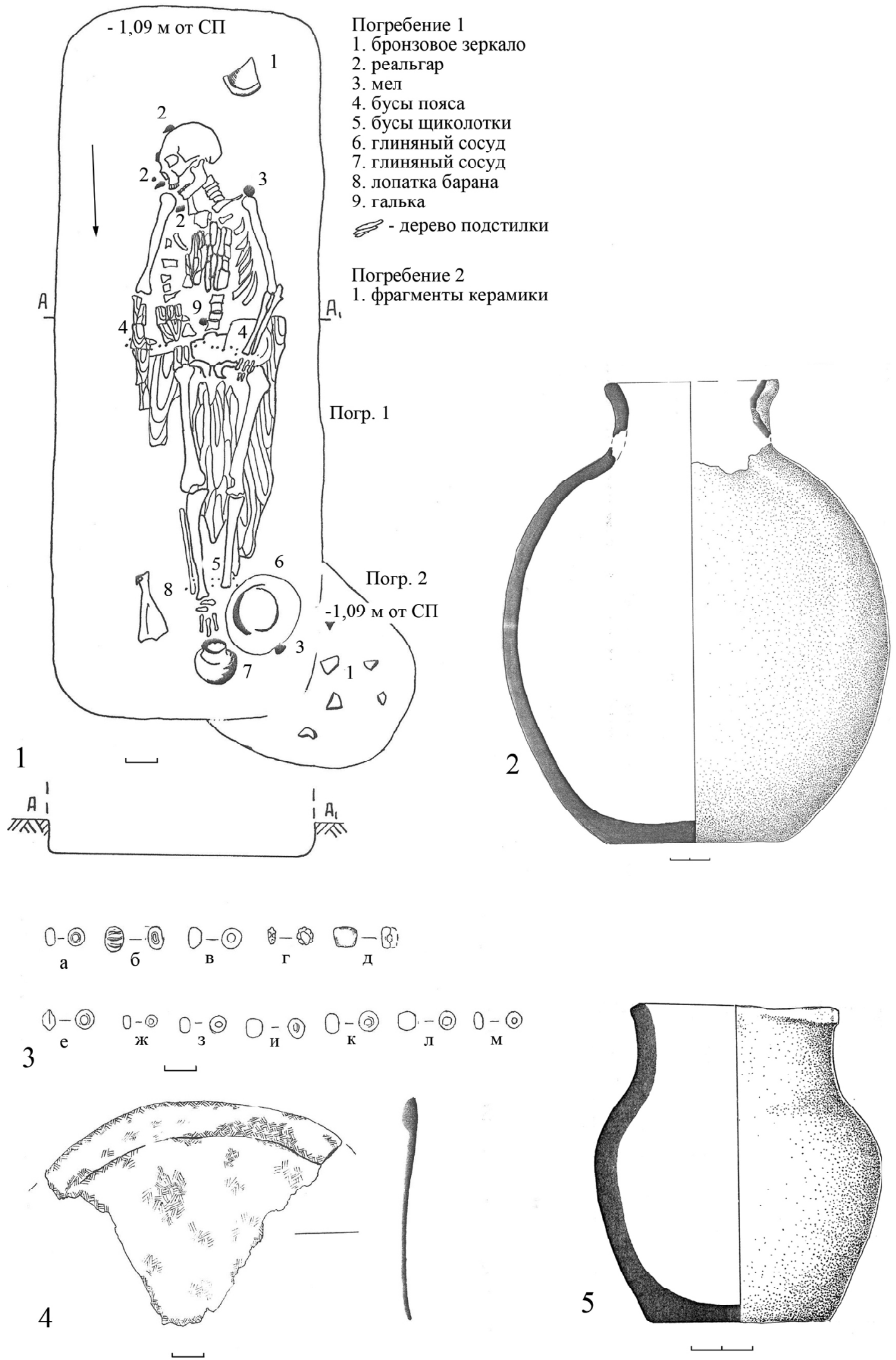

Рис. 2. Раннесарматское погребение. Могильник Шляховский II: 1 - курган 4, погребение $1 ; 2$ - глиняный горшок; 3 - стеклянные бусы; 4 - бронзовое зеркало; 5 - глиняный горшок 

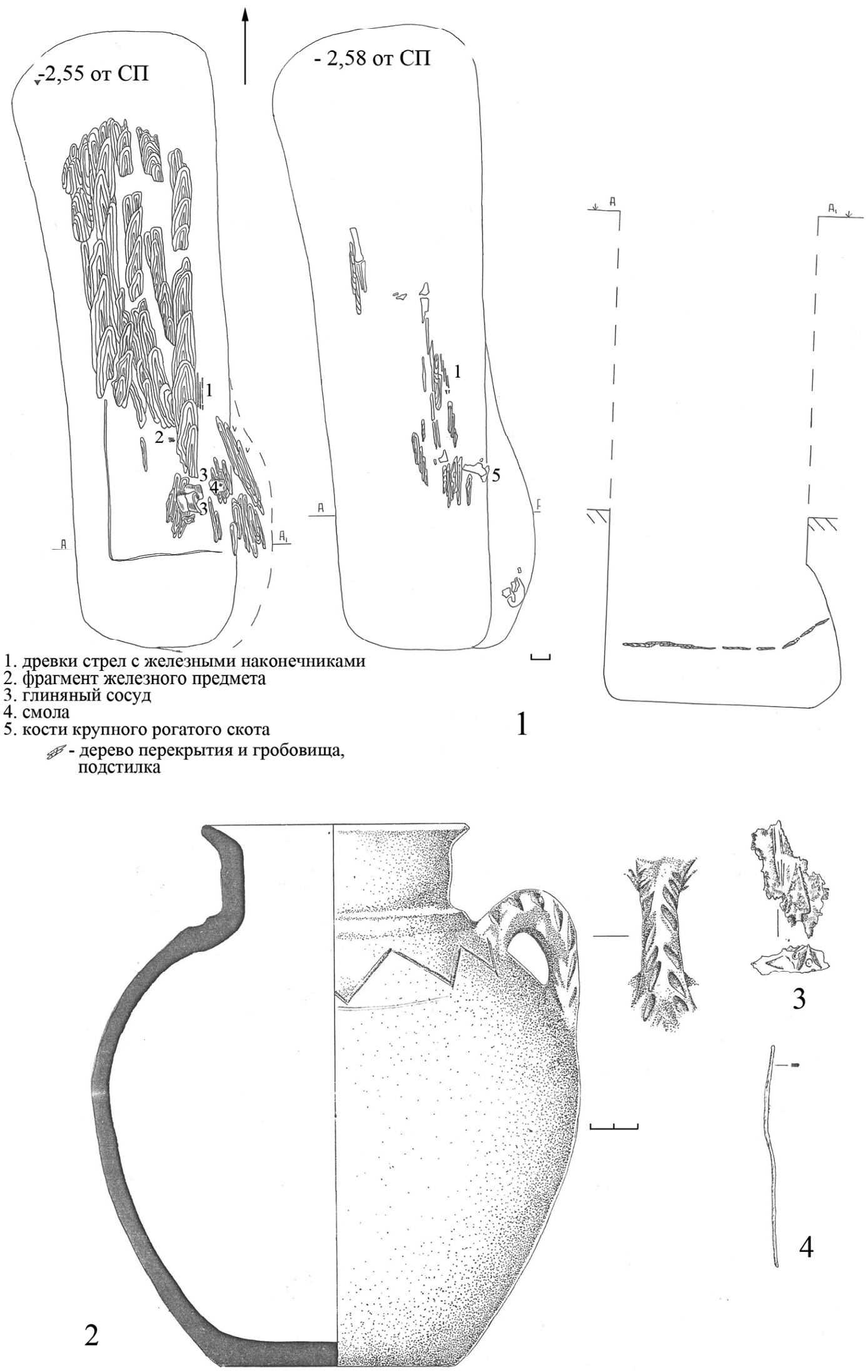

Рис. 3. Раннесарматское погребение. Могильник Шляховский III:

1 - курган 2, погребение $1 ; 2$ - глиняный кувшин; 3 - железные наконечники стрел; 4 - древко стрелы 

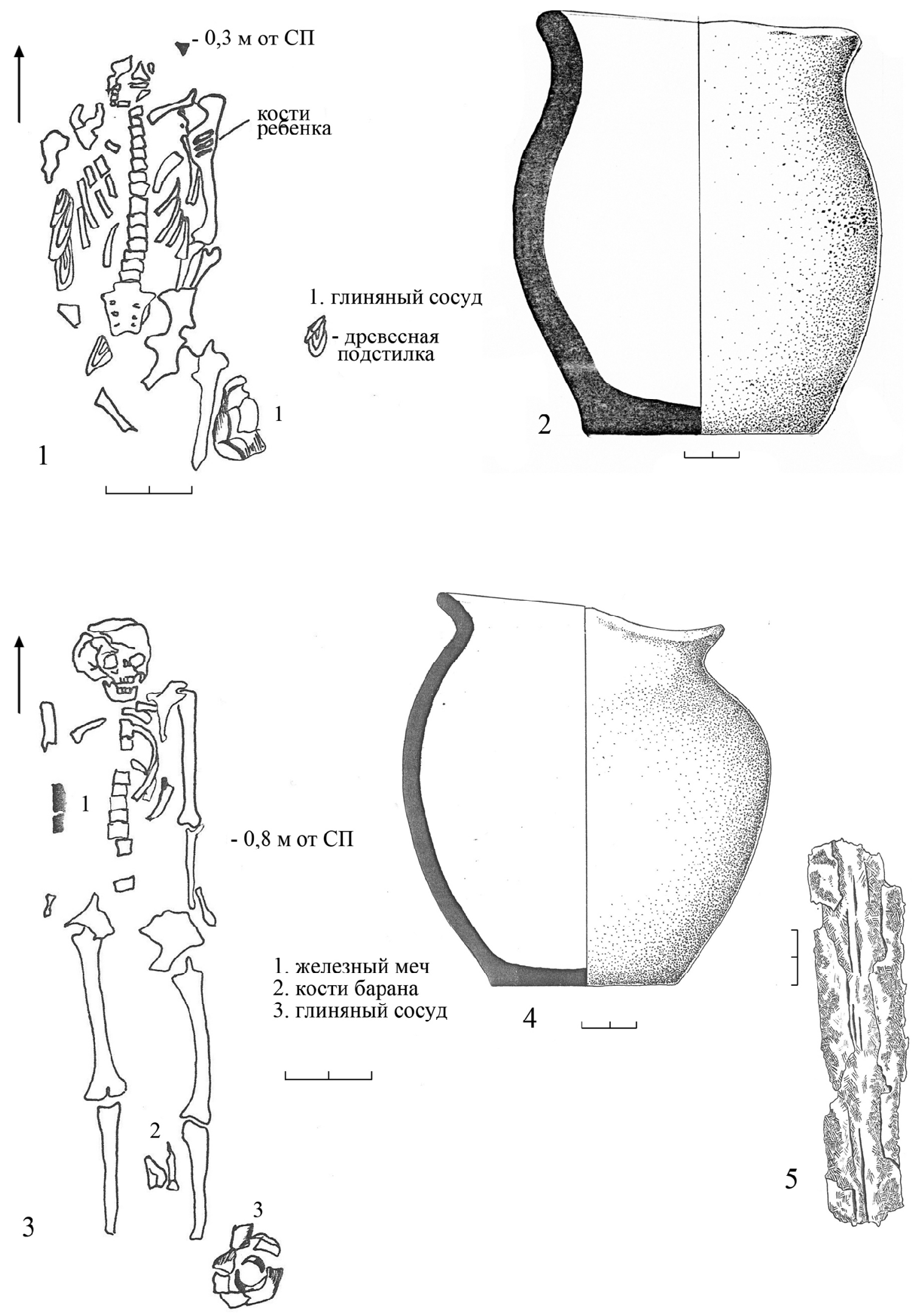

Рис. 4. Погребения позднесарматского времени. Могильник Шляховский III:

1 - курган 5, погребение 2; 2 - глиняный горшок; 3 - курган 7, погребение 2; 4 - глиняный горшок; 5 - обломок железного меча 
V.M. Klepikov. Funerary Monuments of Shlyakhovsky Burial Mound of the Early Iron Age

\section{СПИСОК ЛИТЕРАТУРЫ}

Алексеева Е. М. (1978). Античные бусы Северного Причерноморья. М. : Наука. 105 с. (САИ ; вып. Г 1-12).

Дворниченко В. В. (1981). Погребения предскифского времени на Нижней Волге // КСИА. № 170. С. 59-64.

Клепиков В. М. (1994). Погребения позднеэнеолитического времени у хутора Шляховский в Нижнем Поволжье // Российская археология. №3. С. 97-102.

Клепиков В. М. (2002). Сарматы Нижнего Поволжья в IV-III вв. до н. э. Волгоград : Изд-во ВолГУ. $216 \mathrm{c}$.

Клепиков В. М. (2014). Раннесарматские погребения Нижнего Поволжья с северной ориентировкой // Нижневолжский археологический вестник. Вып. 14. С. 51-56.

Круглов Е. В., Клепиков В. М. (1993). Средневековые памятники из Фроловского района Волгоградской области // Древности Волго-Донских степей : сб. науч. ст. Вып. 6. Волгоград : Изд-во ВолГУ. С. 138-151.

Лукьяшко С. И. (1999). Предскифский период на Нижнем Дону // Донские древности. Вып. 7. Азов : Азовский краеведческий музей. 240 с.

Мамонтов В. И. (1980). О погребениях позднего этапа срубной культуры в Нижнем Поволжье и Волго-Донском междуречье // Российская археология. № 1. С. 175-194.

Моргунова Н. Л., Гольева А. А., Краева Л. А., Мещеряков Д. В., Турецкий М. А., Халяпин М. В., Хохлова О. С. (2003). Шумаевские курганы Оренбург : Изд-во ОГПУ. 392 с.

Скрипкин А. С. (1990). Азиатская Сарматия. Проблемы хронологии и ее исторический аспект Саратов : Изд-во Сарат. ун-та. 299 с.

\section{REFERENCES}

Alekseeva E. M. (1978). Ancient beads of the Northern Black Sea. Moscow, Nauka Publ. 105 p. (SAI; iss. G 1-12). (in Russian).

Dvornichenko V. V. (1981). Burial pre-Scythian time in the Lower Volga region. KSIA, no. 170, pp. 5964. (in Russian).

Klepikov V.M. (1994). Burials of late Eneolithic time at the village of Slagowski in the Lower Volga region. Russian archaeology, no. 3, pp. 97-102. (in Russian).

Klepikov V.M. (2002). Sarmatians of the Lower Volga Region in the $4^{\text {th }}-3^{\text {rd }}$ Centuries $B C$. Volgograd, Izd-vo VolGU. 216 p. (in Russian).

Klepikov V.M. (2014). The early Sarmatian burials in the Lower Volga region with a focus on the North. The Lower Volga archaeological bulletin, iss. 14, pp. 51-56. (in Russian).

Kruglov E.V., Klepikov V.M. (1993). Medieval monuments of the Frolovsky district of the Volgograd region. Antiquities of Volga-Don steppes: collected articles, iss. 6. Volgograd, Izd-vo VolGU, pp. 138-151. (in Russian).

Lukyashko S.I. (1999). Pre-Scythian period on the Lower Don. Don antiquities, iss. 7. Azov, Azovskiy krayevedcheskiy muzey. 240 p. (in Russian).

Mamontov V.I. (1980). The burials of late log culture in the Lower Volga and the Volga-Don interfluve. Russian archaeology, no. 1, pp. 175-194. (in Russian).

Morgunova N.L., Golyeva A.A., Kraeva L.A., Meshcheryakov D.V., Turetskiy M.A., Khalyapin M.V., Khokhlova O.S. (2003). Chumaevsky mounds. Orenburg, Izd-vo OGPU. 392 p. (in Russian).

Skripkin A.S. (1990). Asian Sarmatia. Problems of chronology and its historical aspect. Saratov, Izd-vo Sarat. un-ta. 299 p. (in Russian).

\section{Information about the Author}

Valery M. Klepikov, Associate Professor, Department of Archaeology, Foreign History and Tourism, Volgograd State University, Prosp. Universitetsky, 100, 400062 Volgograd, Russian Federation, valery.klepikov@mail.ru, adsi@volsu.ru.

\section{Информация об авторе}

Валерий Михайлович Клепиков, доцент кафедры археологии, зарубежной истории и туризма, Волгоградский государственный университет, просп. Университетский, 100, 400062 г. Волгоград, Российская Федерация, valery.klepikov@mail.ru, adsi@volsu.ru.

Citation. Klepikov V.M. (2016). Funerary Monuments of Shlyakhovsky Burial Mound of the Early Iron Age. The Lower Volga Arhaeological Bulletin, vol. 15, no. 1, pp. 95-104. (in Russian). 